\title{
RELIABILITY AND COST BENEFITS ASSESSMENT OF WIND ENERGY CONVERSION SYSTEMS
}

\author{
L. A. TALAT \\ ${ }^{I}$ Ass. professor, Electric Power and Machines Department, Faculty of \\ Engineering, Helwan University
}

(Received August 16, 2011 Accepted October18, 2011)

This paper presents a probabilistic approach based on the convolution technique to assess the long-term performance of a Wind Energy Conversion System (WECS) for both stand-alone and grid-linked applications. A methodology is developed to use the proposed model to determine the maximum WECS installed capacity for a given number of turbines on a wind farm to satisfy the load with a certain Expected Energy Not Supplied (EENS). The technique is new in that it uses a simple procedure to estimate the joint probability distribution function of the total available wind power and that of the turbines operating modes due to hardware failure. Analytical expressions are developed to assess the reliability and cost benefits in electric power systems. The proposed method is applied to the IEEE Reliability Test System (IEEE-RTS ).

KEYWORDS: Wind energy conversion system, reliability evaluation, cost benefits assessment.

\section{INTRODUCTION}

Utilization of renewable energy, such as that provided by the wind, for electric power generation is being given serious consideration around the world due to the global environmental concerns associated with conventional energy sources. The main reason is that conventional fuels are limited and expensive, where as these other forms, are limitless and cheap to operate although expensive in capital cost. Wind energy is potentially one of the most promising and trial systems are in operation.

Most of the reported work on modeling wind power generation and on the use of such models for reliability evaluation is in the analytical domain [1,2]. The most obvious deficiency of analytical method is that the chronological characteristics of wind velocity and its effects on wind power output can not be considered. Sequential Monte Carlo simulation, on the other hand, has been proven to be a more effective approach to incorporate these considerations in the adequacy assessment of systems including the Wind Energy Conversion Systems (WECS) [3, 4]. Two risk - based capacity factors designated as load carrying capacity benefit ratio and Equivalent Capacity Rate (ECR) are introduced in [5,6]. The development of a general probabilistic model of an autonomous wind energy conversion system connected to a load and battery storage is described in [7]. A sequential Monte Carlo Simulation (MCS) procedure is used in [8] to assess the adequacy of the combined generating systems. The impact of energy storage on power system reliability performance is investigated in $[9,10]$ using example systems containing wind energy and solar energy.

This paper presents two cases to assess the generation adequacies of power systems including WECS using a proposed method, taking account of two objectives 
of installing WECS. One objective is to replace the conventional power plant by WECS, and other one is installing WECS to meet the load growth and maintain the system adequacy. The Loss Of Load Expectation (LOLE) and Energy Expected Not Supplied (EENS) are calculated as the adequacy index. Wind power penetration levels and the growth rate of annual peak load are studied in details to evaluate the cost benefits of WECS. A probabilistic approach based on the convolution technique to assess the long - term performance of a (WECS) for both stand - alone and grid linked applications is proposed. A new method for computing the energy performance of (WECS) and the reliability analysis is performed by the use of the Energy Index of Reliability (EIR) directly related to energy expected not supplied. Analytical expressions are developed to obtain the power generated and cost - benefits. The generation models and the load models employed enable the study period to range from one year to one particular hour - of day, thus allowing the inclusion of the time value of energy as appropriate in economic assessments. The proposed method is illustrated in case study with the IEEE Reliability Test System. The results are presented in section 6 .

\section{WIND ENERGY CONVERSION SYSTEM}

The basic working principal of Wind Energy Conversion System (WECS) consists of two energy conversion processes. The wind turbine rotor extracts kinetic energy from wind and converts it into mechanical energy at the rotor shaft. The generator converts mechanical power into electrical power. Electrical power is delivered to the main grid system to share the system load. The symbolic representation of the general working principle of wind energy conversion system is shown in Fig. 1.

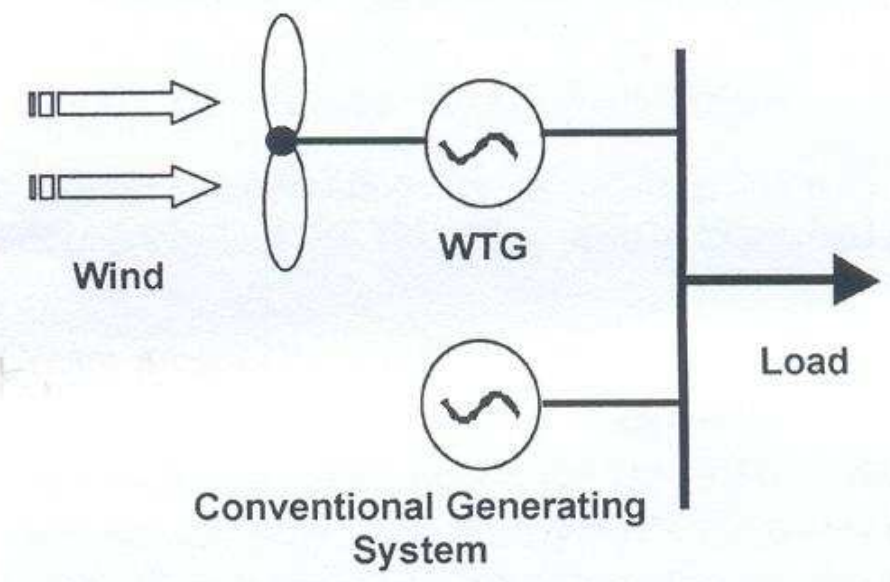

Fig.1. Overall System Configuration

\subsection{WECS Model}

The wind speed distribution for selected sites as well as the power output characteristic of the chosen wind turbine are the factors that have to be considered to determine the WECS power output. 
Since the wind speed ( $\mathrm{V}$ ) is a random variable, a long - term meteorological data is desirable to describe wind energy potential of the sites. In order to account the variability of wind speed, during the $\mathrm{j}$-th hour $(\mathrm{j}=1,2, \ldots, 24)$ of the $\mathrm{m}$-th month $(\mathrm{m}=1,2, \ldots, 12)$, it is assumed to be characterized by a Weibull distribution with a scale parameter $\alpha_{w}$ and a shape parameter $\beta_{w}$ [11]. Density and distribution probability functions are given by

$$
\begin{aligned}
& f(V)=\frac{\beta_{w}}{\alpha_{w}^{\beta_{w}}} \cdot V^{\beta_{w}-1} \cdot \exp \left[-\left(\frac{V}{\alpha_{w}}\right)^{\beta_{w}}\right] \\
& F(V)=1-\exp \left[-\left(\frac{V}{\alpha_{w}}\right)^{\beta_{w}}\right]
\end{aligned}
$$

For a typical WECS, the power output characteristic can be assumed in such a way that it starts generating at the cut-in wind speed $\mathrm{V}_{\mathrm{ci}}$, the power output increases linearly as the wind speed increases from $V_{c i}$ to the rated wind speed $V_{R}$. The rated power $P_{R}$ is produced when the wind speed varies from $V_{R}$ to the cut-out wind speed $\mathrm{V}_{\text {co }}$ at which the WECS will be shut down for safety. Thus,

$$
P_{w}(V)=\left\{\begin{array}{cc}
\left(\frac{P_{R}}{V_{R}-V_{c i}}\right) .\left(V-V_{c i}\right) & \text { for } V_{c i} \leq V \leq V_{R} \\
P_{R} & \text { for } V_{R} \leq V \leq V_{c o} \\
0 & \text { otherwise }
\end{array}\right.
$$

\section{PROPOSED METHOD}

In addition to the output variations with wind speed, a WTG unit can also suffer a forced outage. In order to recognize this, the operating cycle of a WTG is simulated in the same way as that of a conventional base load-generating unit [12]. The sequential up-down-up cycles of a WTG are combined with the hourly available wind power derived from Eq. (3) to obtain the final hourly available power output. The available power of a WECS at a given hour is the sum of the available power outputs of all the wind turbine generators.

The capacity model for WTG units is modified to account the effect of the failure and repair characteristics of WECS. The cumulative probability of a particular capacity outage state of X MW after a WTG unit of capacity C MW and a modified forced outage rate $\mathrm{U}$ is given by

$$
\operatorname{pr}(\mathrm{X})=(1-\mathrm{U}) \mathrm{pr}^{*}(\mathrm{X})+(\mathrm{U}) \mathrm{pr}^{*}(\mathrm{X}-\mathrm{C})
$$

Where $\mathrm{pr}^{*}(\mathrm{X})$ and $\mathrm{pr}(\mathrm{X})$ denote the cumulative probabilities of the capacity outage state of $\mathrm{X}$ MW before and after the wind unit is modified. The above expression is initialized by setting $\operatorname{pr}^{*}(X)=1.0$ for $X \geq 0$ and $\mathrm{pr}^{*}(X)=0$ otherwise.

The most popular generation reliability index is the Loss Of Load Expectation (LOLE). Energy based indices are now receiving more attention particularly for systems that have energy limitations for studying the replacement of thermal energy by novel forms of generations (e.g. wind, solar).It is useful therefore to evaluate relevant 
energy indices, these include Expected Energy Not Supplied (EENS) and Energy Index of Reliability (EIR).

For each state of the capacity model $\mathrm{C}_{\mathrm{k}}, \mathrm{k}=1,2, \ldots, \mathrm{N}_{\mathrm{c}}$. The expected energy not supplied EENS is given numerically by summing all positive values of $\left(\mathrm{L}_{\mathrm{i}}-\mathrm{C}_{\mathrm{i}}\right)$ where $\mathrm{L}_{\mathrm{i}}$ is the $\mathrm{i}$-th load level and $\mathrm{i}=1,2, . ., \mathrm{N}$, each with equal duration $\Delta \mathrm{T}=\mathrm{T} / \mathrm{N}$, where $\mathrm{T}$ represents the total duration of the observation period. The expected energy not supplied is given by [13]

$$
\text { EENS }=\Delta T \sum_{i=1}^{N} \operatorname{ENS}\left(L_{i}\right)
$$

Where ENS $\left(\mathrm{L}_{\mathrm{i}}\right)$ represents the expected value of the energy not supplied during time interval i. For computation of ENS $\left(\mathrm{L}_{\mathrm{i}}\right)$ we take into account all system outage states, $\mathrm{X}$ $(\mathrm{K})$, which cause capacity deficiency during hour $\mathrm{i}$

$\operatorname{ENS}\left(\mathrm{L}_{\mathrm{i}}\right)=\sum_{K=K_{i}}^{N_{c}}\left[L_{i}-(C-X(K))\right] \operatorname{Pr}(K)$

Where $K_{i}$ is defined such that $X\left(\mathrm{~K}_{\mathrm{i}}\right)$ is the smallest capacity outage that would cause capacity deficiency for a given load $\mathrm{L}_{\mathrm{i}}$. Expression (6) can be rewritten as

ENS $\left(L_{i}\right)=M\left(K_{i}\right)+\left(L_{i}-C\right) \operatorname{Pr}^{*}\left(K_{i}\right)$

Where

$\mathrm{M}\left(\mathrm{K}_{\mathrm{i}}\right)=\sum_{K=K_{i}}^{N_{c}} X(K) \operatorname{Pr}(K)$

The quantity $\mathrm{M}\left(\mathrm{K}_{\mathrm{i}}\right)$ represents mean value of all capacity outages which would cause capacity deficiency during time interval i. Substitution of Eq. (7) in Eq. (5) gives

$$
\text { EENS }=\Delta T \sum_{\mathrm{i}=1}^{\mathrm{N}}\left[\mathrm{M}\left(\mathrm{K}_{\mathrm{i}}\right)+\left(\mathrm{L}_{\mathrm{i}}-\mathrm{C}\right) \operatorname{Pr} *\left(\mathrm{~K}_{\mathrm{i}}\right)\right]
$$

Simultaneously with evaluation of Eq. (9), Loss Load Expectation (LOLE) can be evaluated using

$$
\text { LOLE }=\frac{\Delta T}{T} \sum_{i=1}^{N} \operatorname{Pr}^{*}\left(K_{i}\right)
$$

For efficient application of Eq. (9) and Eq. (10) we suggest that the expected energy produced by each unit is given by the difference in EENS before and after adding the unit. The order of adding units is important and must follow the merit order table. When all units have been added, the final value of EENS gives the system reliability. Also the EIR is given by

$$
\text { EIR }=1-\text { EENS / energy demanded }
$$

\section{RELIABILITY AND COST BENEFITS ASSESSMENT OF WIND ENERGY CONVERSION SYSTEMS}

This paper presents a methodology for reliability and cost benefits assessment of power systems including the WECS. This methodology is briefly described as follows. 


\subsection{Reliability Benefit of Wind Energy}

(a) Construct a capacity model for the WTG units using the WECS model using Eqs. (1) and (3).

(b) The capacity model for the WTG unit is modified to account the effect of the failure and repair characteristic using Eq. (4).

(c) Create a capacity model for the conventional generating facilities using chronological simulation and according to a merit, order table based on rearranges the units from minimum to maximum individual production cost per megawatt-hour.

(d) Create the total system generating capacity model by combining the capacity models obtained in steps (b) and (c). The WTG units are considered base loaded in that energy is supplied whenever the wind is sufficient.

The reliability of the system can be assessed over a long time period by Loss of Load Expectation using Eq. (10) and the Expected Energy Not Supplied (EENS) when all units have been considered using Eq. (9) or the Energy Index of Reliability (EIR) using Eq. (11).

\subsection{Cost Benefit of Wind Energy}

The procedure for determining the WECS benefit is summarized by the following steps:

(a) Define a base case without WECS and calculate:

1- The expected energy output of each unit using the methodology described previously,

2- The total system production cost which is equal to the sum of the expected energy supplied by each unit multiplied by its running cost per kilowatt-hour,

3- The system reliability measured by the Expected Energy Not Supplied (EENS).

(b) Add the WECS to the base case and calculate the same items as in step (a).

(c) Compute the total system production cost of the base case with and without the WECS, the difference will be equal to the fuel savings due to the WECS.

(d) Compare the EENS of the system with and without the WECS. The difference will be equal to the reduction in the expected energy not supplied due to the WECS. The system reliability benefit created by the WECS can be expressed in economic terms by multiplying the EENS reduction by the estimated cost of kilowatt-hours not supplied.

(e) Calculate the total WECS benefit (B) which is given by the fuel savings (S) plus the EENS reduction cost (EC) [13].

$\mathrm{B}=\mathrm{S}+\mathrm{EC}$

\section{TEST SYSTEM}

The application of the proposed method will be illustrated with the IEEE Reliability Test System (IEEE-RTS) [13]. The basic characteristic of the test system is shown in Table 1. 
Table 1. Basic Characteristics of Test System

\begin{tabular}{|c|c|}
\hline Characteristics & IEEE - RTS \\
\hline No. of buses & 24 \\
No. of circuits & 38 \\
No. of units & 32 \\
Installed capacity (MW) & 3405 \\
Peak load (MW) & 2850 \\
Period of study (hrs) & 8736 \\
\hline
\end{tabular}

The case study is divided into three parts, one which is the base case without any Wind Turbine Generators (WTG) case 1, the second includes the generation data in the base case with removing different conventional generating units from the test system and replacing them with (WTG) and without any increase in load model (cases 2, 3 and 4), and the third which adds different sized units to case 1 when the load duration curve is increased by $2 \%$ of the base case (cases 5 and 6 ).

\section{A. Case 1: Base Case}

(1) Generation Data: The generating unit cost data for the IEEE-RTS is shown in Table 2.

(2) Load Data: The load duration curve for the IEEE-RTS is shown in Table 3.

Table 2. IEEE - RTS Generating Unit Cost Data

\begin{tabular}{|l|c|c|c|}
\hline \multicolumn{1}{|c|}{$\begin{array}{c}\text { Unit Size } \\
\text { (MW) }\end{array}$} & No. of Units & Forced Outage Rate & $\begin{array}{c}\text { Cost } \\
\text { (\$/MWH) }\end{array}$ \\
\hline 12 (oil 3) & 5 & 0.02 & 27.60 \\
20 (gas turbine) & 4 & 0.10 & 43.50 \\
50 (hydro) & 6 & 0.01 & 00.00 \\
76 (coal 3) & 4 & 0.02 & 14.40 \\
100 (oil 2) & 3 & 0.04 & 23.00 \\
155 (coal 2) & 4 & 0.04 & 11.64 \\
197 (oil 1) & 1 & 0.05 & 22.08 \\
350 (coal 1) & 2 & 0.08 & 11.40 \\
400 (nuclear) & 0.12 & 06.00 \\
\hline
\end{tabular}

Table 3. IEEE - RTS Load Duration Curve

\begin{tabular}{|c|c|c|c|c|c|c|c|}
\hline Duration & 0.0 & 0.1 & 0.2 & 0.3 & 0.4 & 0.5 & 0.6 \\
\hline Load (MW) & 2850 & 2485 & 2221 & 2051 & 1909 & 1811 & 1709 \\
\hline Duration & 0.7 & 0.8 & 0.9 & 1.0 & & & \\
\hline Load (MW) & 1576 & 1453 & 1333 & 1160 & & & \\
\hline
\end{tabular}

\section{B. Cases 2, 3, and 4: Effect of Removing Different Sized Units}

(1) Generation Data: The generation data in the base case with removing ( $1 \times 20$ MW) gas turbine unit case 2 , or $(1 \times 50 \mathrm{MW})$ hydro unit case 3 , or $(1 \times 100$ MW) oil 2 unit case 4 and replacing them by WECS.

(2) Load Data: For cases 2, 3, and 4 the load data is considered the same as for base case. 


\section{Cases 5 and 6: Effect of System Load}

(1) Generation Data: The total generation data considered is the generating capacity of the base case plus capacity size of WTG units' case 5, or several gas turbine units' case 6 .

(2) Load Data: The new load duration curve is increased by $2 \%$ of the base case.

\section{RESULTS OF TEST SYSTEM}

The results presented in Table 4, show that the generating units of IEEE-RTS are placed in merit order from lower to higher operating cost using the proposed method to evaluate the expected energy supplied by each plant in the system with and without the WECS. The system production costs per year before and after adding 20 MW WECS, and the fuel savings per year due to the WECS are also shown in Table 4. The cost of energy not supplied is assumed to be $0.5 \$$ / KWh. The total WECS benefit (B) using Eq. (12) is $1194.6 \times 10^{3} \$$. Table 4, shows that the $20 \mathrm{MW}$ WECS reduces the EENS and the total energy produced by the wind plant is $82.9 \mathrm{GWh} / \mathrm{yr}$. , and fuel saving per year is $1153.4 \times 10^{3} \$$, therefore, the main contribution of the wind plant is to improve the system reliability.

Table 4. IEEE-RTS Unit Energy, Costs and Fuel Savings With and Without WECS

\begin{tabular}{|c|c|c|c|c|c|c|}
\hline Plant (No.) & $\begin{array}{c}\text { EES } \\
\text { without } \\
\text { WECS }\end{array}$ & $\begin{array}{c}\text { EES with } \\
\text { WECS }\end{array}$ & $\begin{array}{c}\text { Reduction } \\
\text { in (EES) }\end{array}$ & $\begin{array}{c}\text { Costs } \\
\text { without } \\
\text { WECS }\end{array}$ & $\begin{array}{c}\text { Costs with } \\
\text { WECS }\end{array}$ & $\begin{array}{c}\text { Fuel } \\
\text { saving per } \\
\text { year }\end{array}$ \\
\hline Wind & GWh & GWh & GWh & $\$ \times 10^{3}$ & $\$ \times 10^{3}$ & $\$ \times 10^{3}$ \\
\hline Hydro(6) & 2594.592 & 2594.592 & 0.0 & 0.0 & 0.0 & 0.0 \\
\hline Nuclear(2) & 6150.1435 & 6150.143 & 0.0005 & 36900.864 & 36900.860 & 0.004 \\
\hline Coal 1 (1) & 2563.16 & 2546.008 & 17.15 & 29220.024 & 29024.488 & 195.536 \\
\hline Coal 2 (4) & 3103.828 & 3066.1495 & 37.6785 & 36128.558 & 35689.980 & 438.577 \\
\hline Coal 3 (4) & 678071.125 & 664.631 & 13.44012 & 9764.224 & 9570.6845 & 193.539 \\
\hline Oil 1 (3) & 356.462 & 342.936 & 13.526 & 7870.681 & 7572.0156 & 298.665 \\
\hline Oil 2 (3) & 18.6416 & 17.684 & 0.9576 & 428.757 & 406.7235 & 22.033 \\
\hline Oil 3 (5) & 1.12374 & 1.020989 & 0.102751 & 31.015 & 28.17932 & 2.83568 \\
\hline Gas tr.(4) & 0.87258 & 0.8211504 & 0.05143 & 37.957 & 35.7201 & 2.23693 \\
\hline Total & 15466.898 & 15466.980 & 82.907 & 120382.080 & 119228.66 & 1153.424 \\
\hline
\end{tabular}

Table 5, shows the WTG capacity required to maintain the criterion reliability as base case 1 , and the ratio of this capacity to the $20 \mathrm{MW}$ conventional unit capacities removed from the IEEE-RTS, for different WTG forced outage. Table 5, shows that the WTG forced outage has a significant influence on the ability of WTG to replace conventional generating units. In order to meet the adequacy criterion, $60 \mathrm{MW}$ of WTG units are required to replace a 20 MW conventional unit with a WTG forced outage of $20 \%$, but only 40 MW of WTG capacity is required if the WTG forced outage is $2 \%$. 
Table 5. Expected Energy Not Supplied, LOLE, Costs and CRR for Different WTG Forced Outages

\begin{tabular}{|c|c|c|c|c|}
\hline F.O.R.(\%) & EENS(MWh) & LOLE(hrs/year) & Costs(\$) & CRR \\
\hline 0 & 1059.14 & 9.82 & 117951624 & 2 \\
2 & 1062.79 & 9.85 & 118000088 & 2 \\
5 & 999.05 & 8.90 & 116930056 & 3 \\
10 & 1011.86 & 9.03 & 117111328 & 3 \\
15 & 1024.66 & 9.16 & 117292632 & 3 \\
20 & 1037.46 & 9.29 & 117473936 & 3 \\
\hline
\end{tabular}

Table 6, shows the effect of the WECS Forced Outage Rate (F.O.R.) for a fixed penetration level equal to $2.9 \%$ when $100 \mathrm{MW}$ is removed and the corresponding system EENS is obtained. The reliability indices at fixed penetration level as shown in Table 6, can be further improved when wind farms with lower WTG forced outage are used .

Table 6. EENS, LOLE, and Costs when 100 MW Conventional Unit is Replaced with WECS for Different WTG Forced Outages

\begin{tabular}{|c|c|c|c|}
\hline F.O.R. (\%) & EENS $($ MWh) & LOLE $(\mathbf{h r s} /$ year) & Costs $\mathbf{( \$ )}$ \\
\hline 0 & 1648.88 & 13.63 & 114432.280 \\
2 & 1661.53 & 13.72 & 114551.224 \\
5 & 1680.53 & 13.86 & 114729.640 \\
10 & 1712.18 & 14.09 & 115027.000 \\
15 & 1743.83 & 14.32 & 115324.368 \\
20 & 1775.49 & 14.55 & 115621.744 \\
\hline
\end{tabular}

Figure 2, shows the Replacement Ratio versus the WTG Forced Outage Rate of the capacity removed from the IEEE- RTS.

Figure 2, shows that $60 \mathrm{MW}$ and $150 \mathrm{MW}$ of WECS are required to replace a 20MW and 50MW unit, respectively at a WTG F.O.R equal to 5\%.The capacity replacement ratio in these cases is 3 . This ratio increases as the WTG F.O.R increases too. 


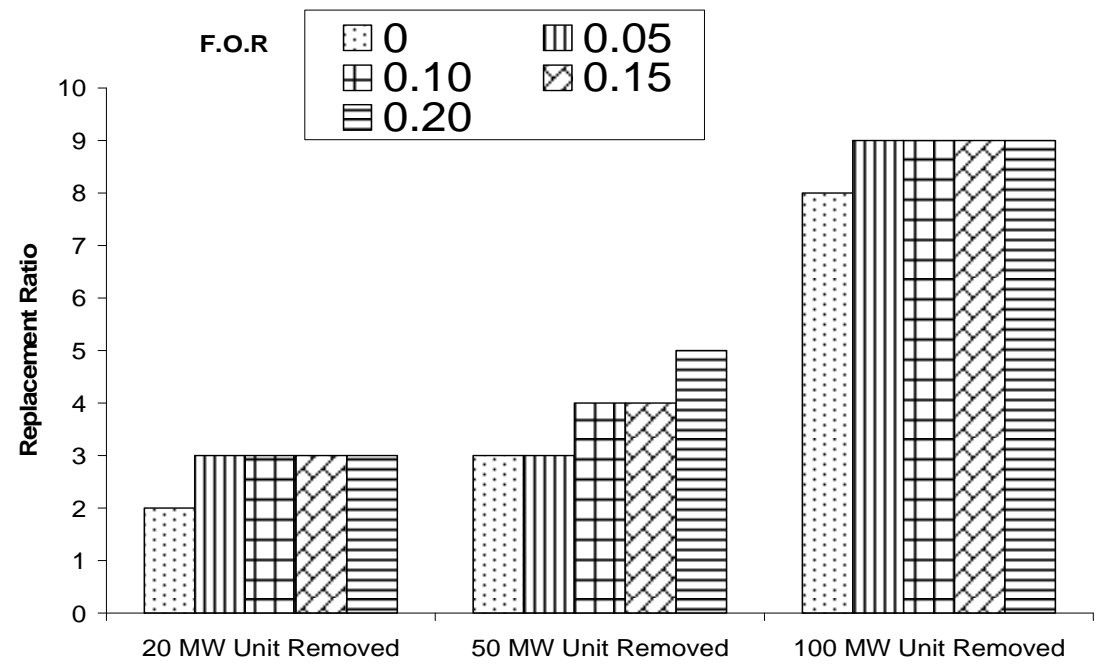

Fig. 2. Replacement Ratio versus the WTG Forced Outage Rate of Unit Removed

Table7. Energy Supplied, Reliability, Cost and Fuel Saving for Different Cases

\begin{tabular}{|l|c|c|c|c|c|c|}
\hline & Case 1 & Case 2 & Case 3 & Case 4 & Case 5 & Case 6 \\
\hline Peak Load (MW) & 2850 & 2850 & 2850 & 2850 & 2907 & 2907 \\
\hline Inst.Capacity (MW) & 3405 & 3445 & 3505 & 4205 & 3585 & 3465 \\
\hline Penetration Level \% & - & 1.74 & 4.28 & 21.4 & 5.02 & - \\
\hline Energy Suppli.(MWh) & 15466898 & 15466965 & 15466895 & 15467159 & 15776307 & 15776295 \\
\hline EENS (MWh) & 1066.46 & 999.06 & 1065.64 & 802.25 & 1015.75 & 1027.86 \\
\hline LOLE( hrs/year) & 9.393 & 8.903 & 8.802 & 9.61 & 8.481 & 8.864 \\
\hline Total Running Cost(\$) & 120382080 & 116930056 & 117915104 & 80411016 & 114831672 & 124958336 \\
\hline Fuel Saving (\$) & & 3452024 & 2466976 & 39971064 & 10126664 & - \\
\hline Eng. Index of R.(EIR) & 0.999931 & 0.999935 & 0.999931 & 0.999948 & 0.9999936 & 0.999935 \\
\hline
\end{tabular}

The results presented in Table 7, shows the energy supplied, expected energy not supplied, LOLE, total running cost, fuel saving and energy index of reliability for all cases of the test system (IEEE-RTS).

The expected energy not supplied (EENS) of case 2 in Table 7, was 999.06 MWh and this value is less than case 1 and the total running cost decreased too. Cases 2,3 and 4 respectively are performed to see the effect of removing 20MW gas turbine unit, or 50MW hydro unit, or 100MW oil 2 unit, and replacing them by WECS on EENS and total running cost. It is found that the WECS reduces the EENS and running cost in all cases. Cases 5 and 6 respectively are performed to see the effect of adding $180 \mathrm{MW}$ of WTG units and $3 \times 20 \mathrm{MW}$ gas turbines on EENS and total running cost. It is found that the WTG units reduce the EENS and the total running cost too. 


\section{CONCLUSION}

This paper has presented a new method for the evaluation of the maximum WECS installed capacity for a given number of turbines on a wind farm to satisfy the load with certain reliability. The technique is new in that it uses a simple procedure to estimate the joint probability distribution function of the total available wind power and that of the turbines operating modes due to hardware failure. The great benefit of this technique can also be used directly in an economic assessment of the operation cost of each unit of the system. The proposed method has been tested on the IEEERTS. The following points may be noted from these studies:

1- The proposed technique is relatively simple; it takes into account the intermittent nature of the wind energy, the probabilistic nature of forced outages, and the fuel costs in the system.

2- The case study using the proposed model shows that wind generation within certain level of penetration indeed improved system reliability and the fuel savings (Table 4).

3- The WECS running cost per plant tends to decrease as the WECS penetration in the system increases.

4- The impact of replacing conventional generating units by WECS and maintaining the system generating capacity adequacy criterion, was determined. The capacity replacement ratio increases as the WTG forced outage rate in the system increases (Table 5).

5- The capacity replacement ratio depends upon the unit capacity that it displaces and the WTG forced outage rate (Fig. 2).

6- At fixed penetration level the EENS and the running costs increases as the WTG forced outage rate in the system increases (Table 6).

7- The WECS energy contribution has a greater impact on economics than on the EENS.

8- The WECS running cost depends greatly upon the type of fuels that it displaces; therefore, the plant fuel cost is the most important parameter in assessing the WECS economic value (Table 7).

9- The EENS reduction due to WECS becomes important when the cost of energy not supplied is very high compared with the conventional plant running costs.

10- The WECS cost tends to increase as the demand increases.

The models, methodologies and results presented in this paper can assist power system planners and utility managers to quantitatively assess the capacity benefits of WECS and provide useful input to the managerial decision process.

\section{REFERENCES}

1. Giorsetto P. and Utsurogi K., "Development of a New Procedure for Reliability Modeling of Wind Turbine Generators ", IEEE Transaction on Power Apparatus and Systems, Vol. 102, No. 1, pp. 134-143, 1983.

2. Singh C. and Gonzalez A., "Reliability Modeling of Generation System Including Unconventional Energy Sources", IEEE Transaction on Power Apparatus and Systems, Vol. 104, No. 5, pp. 1049-1056, 1985. 
3. Billinton R., Chen H. and Ghajar R., "A Sequential Simulation Technique for Adequacy Evaluation of Generating Systems Including Wind Energy”, IEEE/PEC Winter Meeting, 96 WM044-8EC, 1996.

4. Billinton R., Chen H. and Ghajar R., "Time-Series Models for Reliability Evaluation of Power Systems Including Wind Energy", Microelectronics and Reliability, Vol. 36, No. 9, pp. 1253-1261, 1996.

5. Billinton R. and Chen H., "Assessment of Risk-Based Capacity Benefit Factors Associated With Wind Energy Conversion Systems", IEEE Transaction on Power Systems, Vol. 13, No.3, pp. 1191-1196, 1998.

6. Wangdee W. and Billinton R., "Considering Load -Carrying Capability and Wind Speed Correlation of WECS in Generation Adequacy Assessment", IEEE Transactions on Energy Conversion, Vol.21,No.3, pp.734-741, 2006.

7. Karaki S., Chedid R., and Ramadan R., "Probabilistic Performance Assessment of Wind Energy Conversion Systems", IEEE Transactions on Energy Conversion, Vol.14, pp. 217-224, 1999.

8. Billinton R. and Bai G.,"Generating Capacity Adequacy Associated with Wind Energy“, IEEE Transactions on Energy Conversion, Vol.19, No.3, pp.641-646, 2004.

9. Hu P., Karki R., and Billinton R., "Reliability Evaluation of Generating Systems Containing Wind Power and Energy Storage", IET Generation Transmission and Distribution, Vol. 3, pp. 783-791, 2009.

10. Zheng R. and Zhong J., "Generation Adequacy Assessment of Power Systems With Wind Turbine and Energy Storage", Proceedings of the Innovative Smart Grid Technologies (ISGT), pp. 1-6, 2010.

11. Billinton R. and Allan R., "Reliability Evaluation of Engineering Systems: Concepts and Techniques", Pitman Book, 1983.

12. Billinton R. and Allan R., "Reliability Evaluation of Power Systems" 2nd. Ed., New York: Plenum, 1996.

13. Billinton R. and Allan R., "Reliability Assessment of Large Electric Power Systems", USA, 1988.

\section{تقييم الاعتمادية و عائد النفع من الطاقة الكهريية الناتجة من طواحين الهواء}

يقدم هذا البحث طريقة تطبيقية لاستخدام منظومة الطاقة الكهربية الناتجة من طواحين الهواء، التقنية المقترحة تعتمد على تقييم لأداء طويل الأمد في حالتي وجود هذه الطواحين بصورة منفردة (نظام معزول) أو ربطها بشبكة

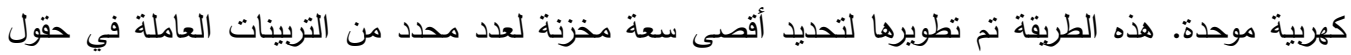
طاقة الرياح وذلك لتحقيق الحمل المطلوب عند الطاقة المحدة و الغير مستفادة المتوقعة. التقنية المستخدمة في مني هذا البحث تقنية جديدة مبسطة تعتمد على توقع دالة احتمالية التوزيع للقدرة الكلية المتاحة من هذه الطواحين عند تمثيل تلك الطواحين تحت ظروف الفشل الخارج عن الإرادة. إن التعبير الرياضي نم تطويرة لكي يقيم الأعتمادية و عائد النفع في منظومة القوى الكهربية. وقد نم تطبيق الطريقة المقترحة على نظام اختبار (IEEE- RTS) 